\title{
Desorption of hydroxyl radicals in the vacuum ultraviolet photolysis of amorphous solid water at $90 \mathrm{~K}$
}

\section{$\operatorname{AUTHOR}(\mathrm{S})$ :}

Hama, Tetsuya; Yabushita, Akihiro; Yokoyama, Masaaki; Kawasaki, Masahiro; Andersson, Stefan

\section{CITATION:}

Hama, Tetsuya ...[et al]. Desorption of hydroxyl radicals in the vacuum ultraviolet photolysis of amorphous solid water at 90 K. JOURNAL OF CHEMICAL PHYSICS 2009, 131(5): 054508.

\section{ISSUE DATE:}

2009-08

URL:

http://hdl.handle.net/2433/109883

\section{RIGHT:}

Copyright 2009 American Institute of Physics. This article may be downloaded for personal use only. Any other use requires prior permission of the author and the American Institute of Physics. The following article appeared in JOURNAL OF CHEMICAL PHYSICS 131, 054508 (2009) and may be found at http://link.aip.org/link/JCPSA6/v131/i5/p054508/s1 


\title{
Desorption of hydroxyl radicals in the vacuum ultraviolet photolysis of amorphous solid water at $90 \mathrm{~K}$
}

\author{
Tetsuya Hama, ${ }^{1}$ Akihiro Yabushita, ${ }^{1}$ Masaaki Yokoyama, ${ }^{1}$ Masahiro Kawasaki, ${ }^{1, a)}$ and \\ Stefan Andersson ${ }^{2}$ \\ ${ }^{1}$ Department of Molecular Engineering, Kyoto University, Kyoto 615-8510, Japan \\ ${ }^{2}$ Leiden Observatory, Leiden University, P.O. Box 9513, 2300 RA Leiden, The Netherlands \\ and Gorlaeus Laboratories, Leiden Institute of Chemistry, Leiden University, \\ P.O. Box 9502, 2300 RA Leiden, The Netherlands
}

(Received 16 January 2009; accepted 9 July 2009; published online 6 August 2009)

\begin{abstract}
We have studied the desorption dynamics of $\mathrm{OH}$ radicals from the $157 \mathrm{~nm}$ photodissociation of amorphous solid water (ASW) as well as $\mathrm{H}_{2} \mathrm{O}_{2}$ deposited on an ASW surface at $90 \mathrm{~K}$. The translational and internal energy distributions of $\mathrm{OH}$ were measured using resonance-enhanced multiphoton ionization methods. These distributions are compared to reported molecular dynamics calculations for the condensed phase photodissociation of water ice and also reported results for the gas phase photodissociation of $\mathrm{H}_{2} \mathrm{O}$ at $157 \mathrm{~nm}$. We have confirmed that $\mathrm{OH}$ radicals are produced from two different mechanisms: one from primary photolysis of surface $\mathrm{H}_{2} \mathrm{O}$ of ASW, and the other being secondary photolysis of $\mathrm{H}_{2} \mathrm{O}_{2}$ photoproducts on the ASW surface after prolonged irradiation at $157 \mathrm{~nm}$. (C) 2009 American Institute of Physics. [DOI: 10.1063/1.3191731]
\end{abstract}

\section{INTRODUCTION}

Experimental and theoretical studies on the effects of radiolysis by UV photons on pure or mixed water have been extensively reported because of its importance to reaction dynamics and kinetics, atmospheric chemistry, and astrophysics. ${ }^{1-3}$ The first absorption band of water ice (the $\widetilde{A}^{1} B_{1}-\widetilde{X}^{1} A_{1}$ transition) has significant cross section in the 130-165 nm range, ${ }^{4}$ and photodissociation of $\mathrm{H}_{2} \mathrm{O}$ in the gas phase involves two primary processes in the first absorption continuum, ${ }^{5,6}$

$$
\begin{aligned}
& \mathrm{H}_{2} \mathrm{O}+h \nu \rightarrow \mathrm{H}_{2}+\mathrm{O}\left({ }^{1} \mathrm{D}\right), \\
& \mathrm{H}_{2} \mathrm{O}+h \nu \rightarrow \mathrm{H}+\mathrm{OH} .
\end{aligned}
$$

The effects of irradiating pure water ice by UV photons have received much experimental study. ${ }^{7-10}$ Gerakines et al. ${ }^{7}$ observed $\mathrm{OH}, \mathrm{HO}_{2}$, and $\mathrm{H}_{2} \mathrm{O}_{2}$ as products in the condensed phase through infrared spectroscopy after amorphous solid water (ASW) at $10 \mathrm{~K}$ was exposed to UV light ( $\lambda$ $>110 \mathrm{~nm}$ ). Ghormley and Hochanadel ${ }^{8}$ reported the formation of $\mathrm{H}, \mathrm{OH}$, and $\mathrm{H}_{2} \mathrm{O}_{2}$ in the condensed phase after Xedischarge flash photolysis of crystalline ice at $263 \mathrm{~K}$. Experimental works on photon- or electron-stimulated desorption of species from water ice were also reported. Westley et al. ${ }^{9,10}$ investigated the absolute desorption yield from water ice at 35-100 K under irradiation with Lyman- $\alpha$ photons of $10.2 \mathrm{eV}$. Kimmel and co-workers ${ }^{11,12}$ used resonance-enhanced multiphoton ionization (REMPI) methods to study the electron-stimulated desorption of $\mathrm{D}$ and $\mathrm{O}$ atoms and $\mathrm{D}_{2}$ molecules from amorphous $\mathrm{D}_{2} \mathrm{O}$. In addition to the dissociation of water molecules, secondary reactions at

\footnotetext{
${ }^{a)}$ Author to whom correspondence should be addressed. Electronic mail: kawasaki@photon.mbox.media.kyoto-u.ac.jp.
}

the ASW/vacuum interface are also important for the desorption from ASW. Petrik et al. ${ }^{13}$ found that electron-stimulated desorption of $\mathrm{O}_{2}$ occurs via the secondary processes of $\mathrm{OH}$, $\mathrm{HO}_{2}$, and $\mathrm{H}_{2} \mathrm{O}_{2}$ products at the surface/vacuum interface of ASW. Yabushita et al. ${ }^{14-16}$ observed that the photodesorption of cold and hot $\mathrm{H}_{2}$ from ASW is induced by the surface reactions of $\mathrm{H}$ atoms produced in reaction (2).

To understand the photolysis of ASW comprehensively, it is crucial to reveal the contribution of secondary photoproducts. By direct detection of photodesorbed species, the characteristic behavior of ice photolysis may be investigated. Since $\mathrm{OH}$ photoproducts are readily trapped in the ice matrix, $\mathrm{H}_{2} \mathrm{O}_{2}$ was produced on the water ice surface at $90 \mathrm{~K}$ presumably due to recombination of photolytically produced $\mathrm{OH},{ }^{17}$

$$
\mathrm{OH}+\mathrm{OH} \rightarrow \mathrm{H}_{2} \mathrm{O}_{2} .
$$

$\mathrm{H}_{2} \mathrm{O}_{2}$ formed via reaction (3) could be subsequently photodissociated to generate $\mathrm{OH}$ as a secondary photoproduct,

$$
\mathrm{H}_{2} \mathrm{O}_{2}+h \nu \rightarrow 2 \mathrm{OH} \text {. }
$$

Molecular dynamics (MD) calculations by Andersson and co-workers ${ }^{18,19}$ predicted the probabilities of $\mathrm{H}$ atom, $\mathrm{OH}$, and $\mathrm{H}_{2} \mathrm{O}$ desorption from the vacuum ultraviolet (vuv) photolysis of ASW. Öberg et al. ${ }^{20}$ used a vuv lamp emitting in the range of $7.0-10.5 \mathrm{eV}$ to irradiate ices at surface temperatures in the range of $18-100 \mathrm{~K}$ and detected desorbing species such as $\mathrm{H}_{2} \mathrm{O}, \mathrm{OH}, \mathrm{H}_{2}$, and $\mathrm{O}_{2}$. However, experimental results on the details of the mechanism of photodesorption and the kinetic and internal energy distributions of the $\mathrm{OH}$ products have not yet been reported. In the present study, we have investigated translational and internal energy distributions of photodesorbed $\mathrm{OH}$ radicals following the $157 \mathrm{~nm}$ photodissociation of ASW and $\mathrm{H}_{2} \mathrm{O}_{2}$ at $90 \mathrm{~K}$ to reveal the desorption dynamics of $\mathrm{OH}$ radicals, 


$$
\begin{aligned}
& \mathrm{H}_{2} \mathrm{O}(\text { ads })+h \nu(157 \mathrm{~nm}) \rightarrow \mathrm{H}(\mathbf{i})+\mathrm{OH}(\mathbf{i}), \\
& \mathrm{H}_{2} \mathrm{O}_{2} \text { (ads) }+h \nu(157 \mathrm{~nm}) \rightarrow 2 \mathrm{OH}(\mathbf{i})
\end{aligned}
$$

The available energies in units of $\mathrm{kcal} / \mathrm{mol}$ for reactions (5) and (6) at $157 \mathrm{~nm}$ are $E_{\text {avail }}(5)=51.2$ and $E_{\text {avail }}(6)=115.9 \mathrm{kcal} / \mathrm{mol}$. In this work, the notation "ads" stands for condensed phase or adsorbed state, and the thermodynamic data for adsorbed species are taken from those for the solid phase. The notation $\mathbf{i}$ stands for species at the ASW/vacuum interface, and for these species we use the gas phase thermodynamics data. ${ }^{21,22}$ Based on the present results we have proposed two $\mathrm{OH}$ formation mechanisms, reactions (5) and (6). Reaction (6) is appreciable after prolonged vuv irradiation on ASW.

\section{EXPERIMENTAL}

\section{A. Apparatus and preparation of ice films}

Surface photodissociation of ASW at $90 \mathrm{~K}$ was carried out in a high vacuum chamber, which was equipped with two turbo molecular pumps, a pulsed molecular beam, an excimer laser, and a dye laser. The experimental details are described elsewhere. ${ }^{23}$ In brief, a vacuum chamber was evacuated to a base pressure of $10^{-8}$ Torr using two turbomolecular pumps in tandem (Shimadzu, 800 and $50 \mathrm{~L} \mathrm{~s}^{-1}$ ). A circular sapphire substrate sputter coated with a thin polycrystalline film of $\mathrm{Au}(111)$ was supported in the center of the chamber by a liquid-nitrogen-cooled manipulator connected to an $X-Y-Z$ stage. ${ }^{24}$ The temperature of the substrate was controlled to within $1 \mathrm{~K}$. The controller was composed of an alumel-chromel resistance thermometer with cooling by liquid nitrogen and heating from a $0.35 \mathrm{~mm} \mathrm{di-}$ ameter tantalum filament attached to the substrate. The ASW film was prepared by back-filling deposition of water vapor onto the substrate at $90 \mathrm{~K}$ for $60 \mathrm{~min}$ by a pulsed nozzle (general valve) at the rate of $10 \mathrm{~Hz}$ and at 30 Torr stagnation pressure of water vapor. In order to spread water vapor all over the chamber, a flat plate was attached in front of the pulse nozzle. The exposure was typically $1800 \mathrm{~L}$ ( $1 \mathrm{~L}=1 \times 10^{-6}$ Torr s). Unfocused $157 \mathrm{~nm}$ laser (Lambda Physik, OPTexPro) radiation was incident at an angle of about $80^{\circ}$ to the surface normal on the ice surface at a fluence of $<0.1 \mathrm{~mJ} \mathrm{~cm}^{-2}$ pulse ${ }^{-1}$. Neutral $\mathrm{OH}$ photofragments produced by the photolysis laser were subsequently ionized at a distance of $r=2 \mathrm{~mm}$ from the substrate surface, as shown in the schematic diagram of the experimental arrangement (Fig. 1). The $\mathrm{OH}$ photofragments were ionized by $(2+1)$ REMPI via the $D^{2} \Sigma^{-}\left(v^{\prime}=0\right) \leftarrow X^{2} \Pi\left(v^{\prime \prime}=0\right)$ transition at 243.5-244.5 nm and via the $D^{2} \Sigma^{-}\left(v^{\prime}=1\right)$ $\leftarrow X^{2} \Pi\left(v^{\prime \prime}=0\right)$ and $3^{2} \Sigma^{-}\left(v^{\prime}=0\right) \leftarrow X^{2} \Pi\left(v^{\prime \prime}=1\right)$ transitions at $237.5-237.7 \mathrm{~nm}$, and collected with a small mass spectrometer aligned perpendicular to the ice surface. Twophoton absorption cross sections reported by Greenslade et $a l^{25}$ allow us to estimate the ratio of $\left(v^{\prime \prime}=1\right) /\left(v^{\prime \prime}=0\right)$. Radiation at $237-245 \mathrm{~nm}$ was produced by a $\mathrm{Nd}^{3+}$ : yttrium aluminum garnet pumped dye laser (Lambda Physik, SCANmate) with subsequent frequency doubling and mixing in $\mathrm{BBO}$ crystals. $\mathrm{OH}$ can be formed via two different path-

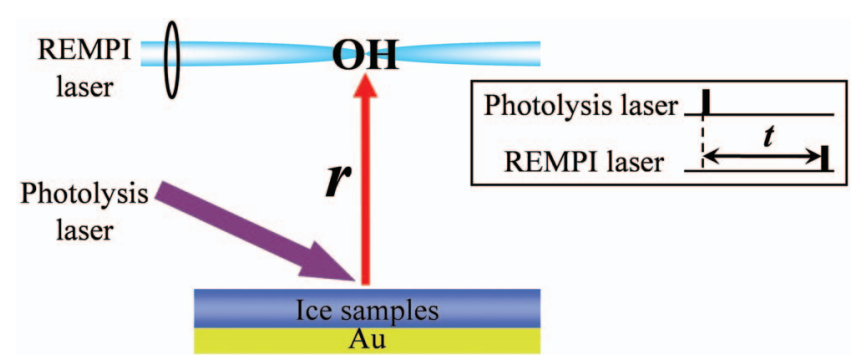

FIG. 1. Schematic illustration of the experiment. OH photofragments from the $157 \mathrm{~nm}$ photodissociation of water ice samples are detected by the REMPI technique. The timing plot for measurement of a time-of-flight (TOF) spectrum is shown in the inset where the delay time $t$ between photolysis and probe laser pulses corresponds to the TOF. $r(=2 \mathrm{~mm})$ is the vertical distance between the disc substrate and the detection point. The 157 $\mathrm{nm}$ photoirradiated area is a disc with a radius of $6 \mathrm{~mm}$.

ways: (a) by direct photolysis of ASW, reaction (5), and (b) by photolysis of $\mathrm{H}_{2} \mathrm{O}_{2}$ photoproducts after prolonged irradiation of ice, reaction (6). To suppress the contribution of $\mathrm{OH}$ photoproducts formed by the secondary photolysis of $\mathrm{H}_{2} \mathrm{O}_{2}$ products on the surface of ASW via reaction (6), the ASW surface was continually refreshed by intermissive exposure to $\mathrm{H}_{2} \mathrm{O}$ vapor. The pulsed valve was opened after each laser shot so as to deposit a fresh layer of ASW.

For the $\mathrm{H}_{2} \mathrm{O}_{2} / \mathrm{H}_{2} \mathrm{O}$ codeposited ice photolysis experiments, a commercially available $\mathrm{H}_{2} \mathrm{O}_{2}$ solution (30\%) was concentrated in a glass container by vacuum distillation and the $\mathrm{H}_{2} \mathrm{O}_{2} / \mathrm{H}_{2} \mathrm{O}$ vapor was deposited on ASW. The exposure of the $\mathrm{H}_{2} \mathrm{O}_{2} / \mathrm{H}_{2} \mathrm{O}$ mixture on ASW was $<10 \mathrm{~L}$ for $330 \mathrm{~s}$ duration at $90 \mathrm{~K}$. Fresh surfaces of $\mathrm{H}_{2} \mathrm{O}_{2}$ cocondensed on ASW were prepared as described above.

All of present photolysis experiments were performed at a sample temperature of $90 \mathrm{~K}$, and the chamber pressure was $5 \times 10^{-7}$ Torr (due to the $\mathrm{H}_{2} \mathrm{O}$ or $\mathrm{H}_{2} \mathrm{O}_{2} / \mathrm{H}_{2} \mathrm{O}$ vapor injection into the chamber).

\section{B. Simulation of time-of-flight spectra of $\mathrm{OH}$ products and REMPI transition factors}

Time-of-flight (TOF) spectra of $\mathrm{OH}$ photoproducts were taken as a function of time $t$ between the photolysis and REMPI laser pulses using a delay generator (Stanford Research) in order to investigate the flight times (and thus translational energies) of the desorbing $\mathrm{OH}$ photoproducts, as shown schematically in Fig. 1. Details regarding the simulation of such TOF spectra have been reported previously. ${ }^{23,26}$ The measured TOF spectra $S\left(a_{i}, t, T_{\text {trans }}\right)$ of the $\mathrm{OH}$ products were fitted to a sum of one or more flux-weighted MaxwellBoltzmann (MB) distributions $S_{\mathrm{MB}}$, each defined by a translational temperature $T_{\text {trans. }}$. The coefficients $a_{i}$ define the relative population associated with each MB component,

$$
\begin{aligned}
& S\left(a_{i}, t, T_{\text {trans }}\right)=\Sigma a_{i} S_{\mathrm{MB}}\left(t, T_{\text {trans }}\right), \\
& S_{\mathrm{MB}}\left(t, T_{\text {trans }}\right)=r^{3} t^{-4} \exp \left[-m r^{2} / 2 k_{B} T_{\text {trans }} t^{2}\right], \\
& P_{\mathrm{MB}}\left(E_{t}\right)=\left(k_{B} T_{\text {trans }}\right)^{-2} E_{t} \exp \left[-E_{t} / k_{B} T_{\text {trans }}\right],
\end{aligned}
$$

where $r$ is the distance between the substrate surface and the REMPI probe region. The MB distribution $P_{\mathrm{MB}}\left(E_{t}\right)$ as a function of translational energy $E_{t}$ is characterized by the 

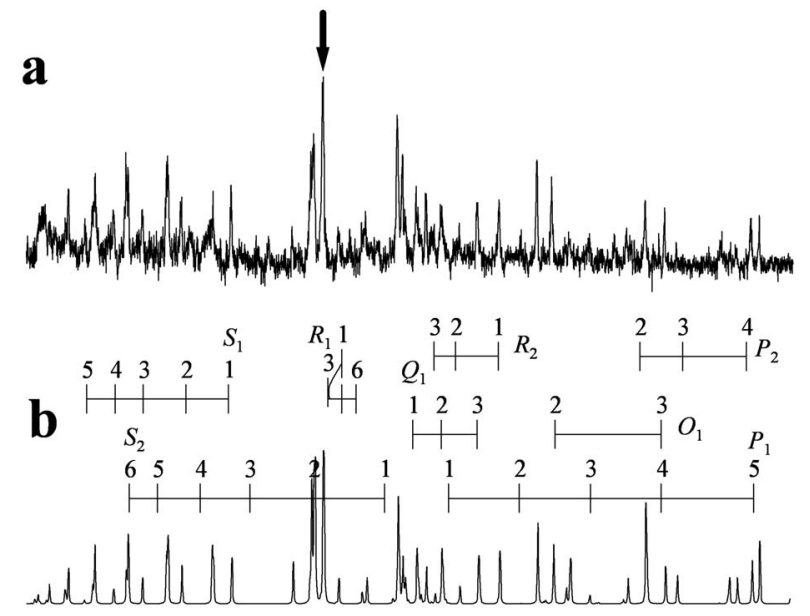

\section{$243.5 \quad 244.0 \quad 244.5 \quad 245.0$ Wavelength / nm}

FIG. 2. (a) REMPI excitation spectrum of the $\mathrm{OH} D^{2} \Sigma^{-} \leftarrow X^{2} \Pi$ $\left(v^{\prime}=0, v^{\prime \prime}=0\right)$ transition from fresh ASW. TOF $=1.5 \mu \mathrm{s}$. (b) A simulated $\mathrm{OH}$ spectrum assuming a Boltzmann distribution with $T_{\mathrm{rot}}=400 \mathrm{~K}$. The arrow is the $R(1)+R(5)$ line used for TOF spectrum measurements.

averaged translational energy $\left\langle E_{t}\right\rangle=2 k_{B} T_{\text {trans }}$, where $k_{B}$ is the Boltzmann constant. ${ }^{27}$

Model calculations were performed as follows. First, $P_{\mathrm{MB}}\left(E_{t}\right)$ is converted from the energy distribution to the TOF distribution using the Jacobian listed by Zimmerman and Ho. ${ }^{28}$ In these calculations we assume that signals come from a disc (vuv photoirradiation area) with a radius of $6 \mathrm{~mm}$. Hence, an effective flight length is given by $\left(r^{2}+R^{2}\right)^{1 / 2}$ and the detection probability is proportional to $2 \pi R d R /\left(r^{2}+R^{2}\right)$. We used $r=2 \mathrm{~mm}$ and $0 \leq R \leq 6 \mathrm{~mm}$. For the angular distribution of the photofragments from the ice surface, $\cos ^{n} \theta$, where $\theta$ is the surface polar coordinate, $n=0$ was adopted in the best-fitting procedures because the parent $\mathrm{H}_{2} \mathrm{O}$ or $\mathrm{H}_{2} \mathrm{O}_{2}$ molecules adsorb randomly on the ASW surfaces. ${ }^{23,26}$ PGOPHER, a program for simulating rotational structure, was used. $^{29}$ The REMPI signals measured at a constant laser power were corrected by the constants for the respective electronic states of $\mathrm{OH}^{25,30}$

\section{RESULTS}

\section{A. $\mathrm{OH}$ radical from the $157 \mathrm{~nm}$ photolysis of fresh amorphous solid water}

Figure 2(a) shows a REMPI spectrum of $\mathrm{OH}(v=0)$ recorded at a fixed delay of $t=1.5 \mu \mathrm{s}$, corresponding to the peak in the TOF profile from the $157 \mathrm{~nm}$ photolysis of fresh ASW. The rotational temperature $T_{\text {rot }}(v=0)$ is estimated to be $400 \pm 100 \mathrm{~K}$ by spectral simulation [Fig. 2(b)]. Figure 3 (a) shows a mixed band REMPI spectrum of $\mathrm{OH}(v=0$ and 1) at $t=1.5 \mu \mathrm{s}$. Figure $3(\mathrm{~b})$ is a simulated mixed band spectrum for $T_{\text {rot }}(v=0)=400 \mathrm{~K}$ and $T_{\text {rot }}(v=1)=300 \mathrm{~K}$. The rotational temperature $T_{\mathrm{rot}}(v=1)$ is estimated to be $300 \pm 100 \mathrm{~K}$ and the population ratio of $v=1 / v=0$ is $0.2 \pm 0.1$ by spectral simulation. Figure 4(a) shows a typical TOF spectrum of $\mathrm{OH}(v=0)$ for the $R(1)+R(5)$ line, which is (a)

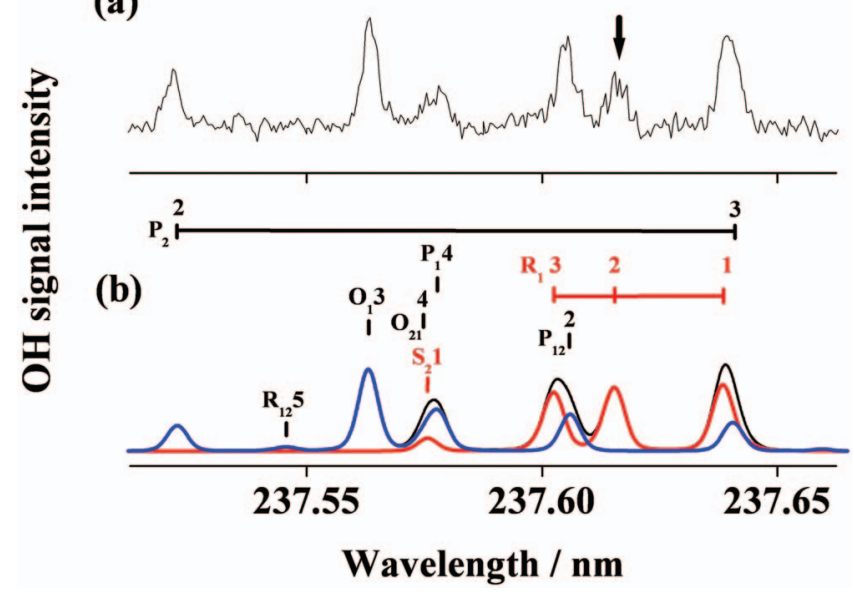

FIG. 3. (a) REMPI excitation spectrum of $\mathrm{OH} D^{2} \Sigma^{-} \leftarrow X^{2} \Pi\left(v^{\prime}=1, v^{\prime \prime}\right.$ $=0)$ and $3^{2} \Sigma^{-} \leftarrow X^{2} \Pi\left(v^{\prime}=0, v^{\prime \prime}=1\right)$. TOF $=1.5 \mu$ s. (b) A simulated spectrum assuming $T_{\text {rot }}(v=0)=400 \mathrm{~K}$ (blue line) and $T_{\text {rot }}(v=1)=300 \mathrm{~K}$ (red line). The experimental conditions are the same as for Fig. 2. The arrow is the $R(2)$ line used for TOF spectrum measurements.

reproduced by two MB distributions with $T_{\text {trans }}(v=0)$ $=7500 \pm 1000 \mathrm{~K}(5 \%$ contribution $)$ and $1300 \pm 300 \mathrm{~K}$ $(95 \%)$. Figure $4(\mathrm{~b})$ shows a typical TOF spectrum of $\mathrm{OH}(v=1)$ for $R(2)$ line, which is reproduced with $T_{\text {trans }}$ $(v=1)=7500 \pm 1000 \mathrm{~K}(10 \%)$ and $1300 \pm 300 \mathrm{~K}(90 \%)$. We found no clear evidence of the formation of vibrationally

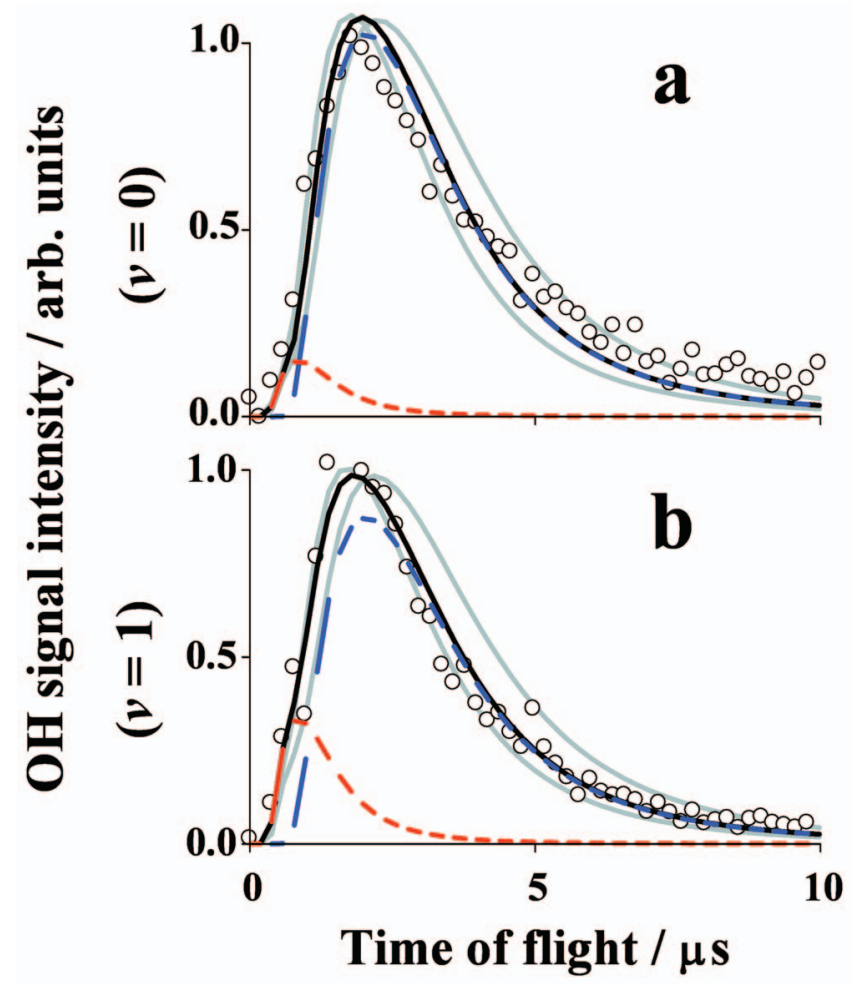

FIG. 4. (a) TOF spectrum of the $R(1)+R(5)$ line in the $\mathrm{OH}$ $D^{2} \Sigma^{-} \leftarrow X^{2} \Pi\left(v^{\prime}=0, v^{\prime \prime}=0\right)$ transition. (b) $R(2)$ line in $\mathrm{OH} 3^{2} \Sigma^{-}$ $\leftarrow X^{2} \Pi\left(v^{\prime}=0, v^{\prime \prime}=1\right)$. The solid black curves are fits to the data derived assuming a MB distribution. (a) $T_{\text {trans }}=7500 \mathrm{~K}(5 \%$ contribution, dashed red line) and $1300 \mathrm{~K}\left(95 \%\right.$, dashed blue line) and (b) $T_{\text {trans }}=7500 \mathrm{~K}(10 \%)$ and $1300 \mathrm{~K}(90 \%)$. Other gray curves show the error bar ranges (see Table I). The experimental conditions are the same as for Fig. 2. 
TABLE I. Contributions (percent) of translational and rotational temperature components of $\mathrm{OH}(v=0,1)$ products.

\begin{tabular}{|c|c|c|c|c|c|}
\hline & \multicolumn{2}{|c|}{$v=0$} & \multicolumn{2}{|c|}{$v=1$} & \multirow[b]{2}{*}{ Population ratio $v=1 / v=0$} \\
\hline & $\begin{array}{c}T_{\text {trans }} \\
(\mathrm{K})\end{array}$ & $\begin{array}{l}T_{\text {rot }} \\
(\mathrm{K})\end{array}$ & $\begin{array}{c}T_{\text {trans }} \\
(\mathrm{K})\end{array}$ & $\begin{array}{l}T_{\text {rot }} \\
(\mathrm{K})\end{array}$ & \\
\hline \multirow[t]{2}{*}{ Fresh ASW } & $7500 \pm 1000(5 \%)$ & & $7500 \pm 1000(10 \%)$ & & \\
\hline & $1300 \pm 300(95 \%)$ & $400 \pm 100^{a}$ & $1300 \pm 300(90 \%)$ & $300 \pm 100^{a}$ & $0.2 \pm 0.1^{\mathrm{a}}$ \\
\hline \multirow[t]{2}{*}{ ASW after $1 \mathrm{hr}$ irradiation } & $7500 \pm 1000(30 \%)$ & & $7500 \pm 1000(40 \%)$ & & \\
\hline & $1300 \pm 300(70 \%)$ & $500 \pm 100^{b}$ & $1300 \pm 300(60 \%)$ & $200 \pm 100^{b}$ & $0.2 \pm 0.1^{b}$ \\
\hline \multirow[t]{2}{*}{$\mathrm{H}_{2} \mathrm{O}_{2}$ on $\mathrm{ASW}$} & $7500 \pm 1000(30 \%)$ & & $7500 \pm 1000(40 \%)$ & & \\
\hline & $1300 \pm 300(70 \%)$ & $500 \pm 100^{b}$ & $1300 \pm 300(60 \%)$ & $200 \pm 100^{b}$ & $0.2 \pm 0.1^{b}$ \\
\hline 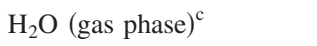 & $\sim 1600$ & 600 & $\cdots$ & 450 & $0.56-1.11^{\mathrm{d}}$ \\
\hline Calculation for water ice $\mathrm{e}^{\mathrm{e}}$ & & & & & $0.3-0.5$ \\
\hline
\end{tabular}

${ }^{\mathrm{a}} \mathrm{TOF}=1.5 \mu \mathrm{s}$.

${ }^{\mathrm{b}} \mathrm{TOF}=0.5 \mu \mathrm{s}$.

${ }^{\mathrm{c}}$ Reference 31.

excited $\mathrm{OH}(v=2)$ in the wavelength region of the $3^{2} \Sigma^{-}$ $\left(v^{\prime}=0\right) \leftarrow X^{2} \Pi\left(v^{\prime \prime}=2\right)$ transition. Table I summarizes these results.

\section{B. $\mathrm{OH}$ radical from the $157 \mathrm{~nm}$ photolysis of fresh $\mathrm{H}_{2} \mathrm{O}_{2}$ cocondensed on amorphous solid water}

Figure 5 shows the typical TOF spectra of (a) $\mathrm{OH}$ $(v=0)$ and (b) $\mathrm{OH}(v=1)$ from the $157 \mathrm{~nm}$ photodissociation of fresh $\mathrm{H}_{2} \mathrm{O}_{2}$ cocondensed on ASW. The OH signal intensities were 1.5-1.8 times stronger than those from fresh ASW.

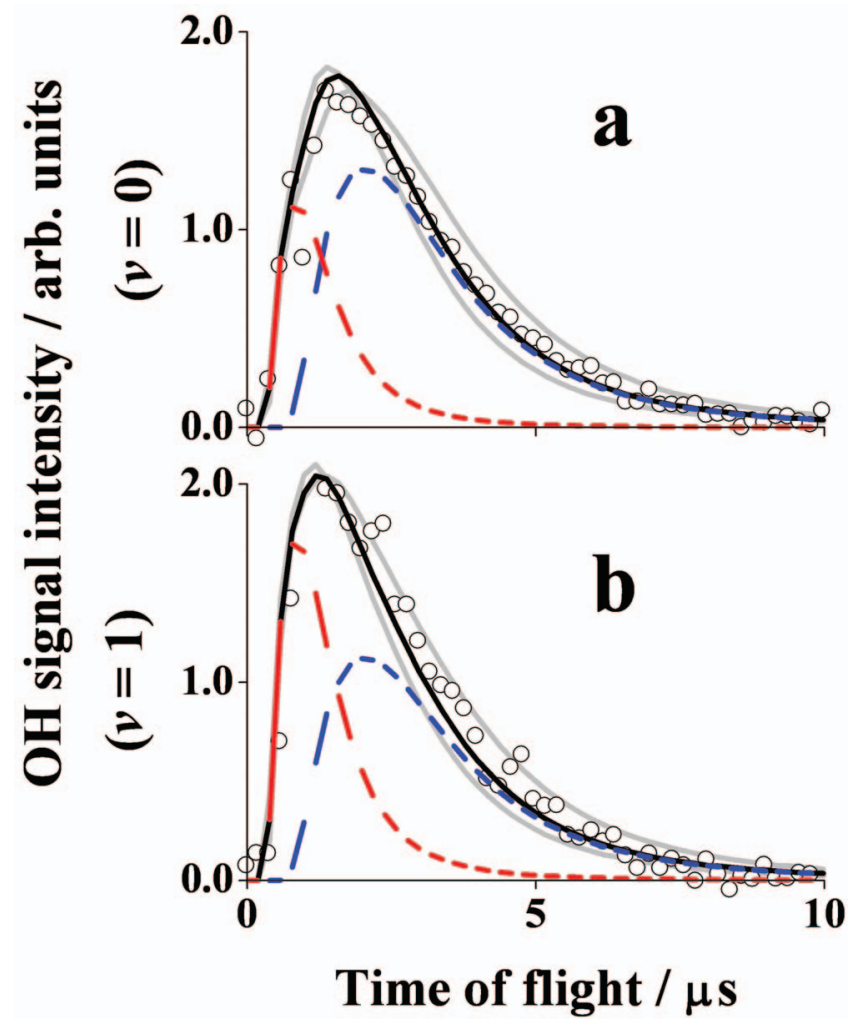

FIG. 5. (a) TOF spectrum of the $R(1)+R(5)$ line in $\mathrm{OH} D^{2} \Sigma^{-} \leftarrow X^{2} \Pi$ $\left(v^{\prime}=0, v^{\prime \prime}=0\right)$ from fresh $\mathrm{H}_{2} \mathrm{O}_{2}$ cocondensed on ASW. (b) The $R(2)$ line in OH $3{ }^{2} \Sigma^{-} \leftarrow X^{2} \Pi\left(v^{\prime}=0, v^{\prime \prime}=1\right)$. The solid black curves are fits assuming (a) $T_{\text {trans }}=7500 \mathrm{~K}(30 \%)$ and $1300 \mathrm{~K}(70 \%)$ and (b) $T_{\text {trans }}=7500 \mathrm{~K}(40 \%)$ and $1300 \mathrm{~K}(60 \%)$. Other gray curves show the error bar ranges (see Table I).

\author{
${ }^{\mathrm{d}}$ References 32 and 33 . \\ ${ }^{\mathrm{e}}$ References 17 and 18
}

These TOF spectra are reproduced by two MB distributions with $T_{\text {trans }}(v=0)=7500 \pm 1000 \mathrm{~K}(30 \%)$ and $1300 \pm 300 \mathrm{~K}$ $(70 \%)$ and $T_{\text {trans }}(v=1)=7500 \pm 1000 \mathrm{~K} \quad(40 \%)$ and $1300 \pm 300 \mathrm{~K}(60 \%)$. Figure 6(a) shows a REMPI spectrum of $\mathrm{OH}(v=0)$ at $t=0.5 \mu \mathrm{s}$, and $T_{\text {rot }}(v=0)$ is estimated to be $500 \pm 100 \mathrm{~K}$ by spectral simulation [Fig. 6(c)]. Figure 7(a) shows a mixed band REMPI spectrum of $\mathrm{OH}(v=0$ and 1$)$ at $t=0.5 \mu \mathrm{s} . T_{\text {rot }}(v=1)$ is estimated to be $200 \pm 100 \mathrm{~K}$ and the population ratio $v=1 / v=0$ is $0.2 \pm 0.1$ by spectral simulation [Fig. 7(c)]. Table I summarizes these results.

\section{C. $\mathrm{OH}$ formation from the $157 \mathrm{~nm}$ photolysis of amorphous solid water after prolonged $157 \mathrm{~nm}$ irradiation}

Figure 8 shows the TOF spectra of (a) $\mathrm{OH}(v=0)$ and (b) $\mathrm{OH}(v=1)$ formed by $157 \mathrm{~nm}$ photolysis of ASW, which were measured after $1 \mathrm{~h}$ photoirradiation without the intermissive

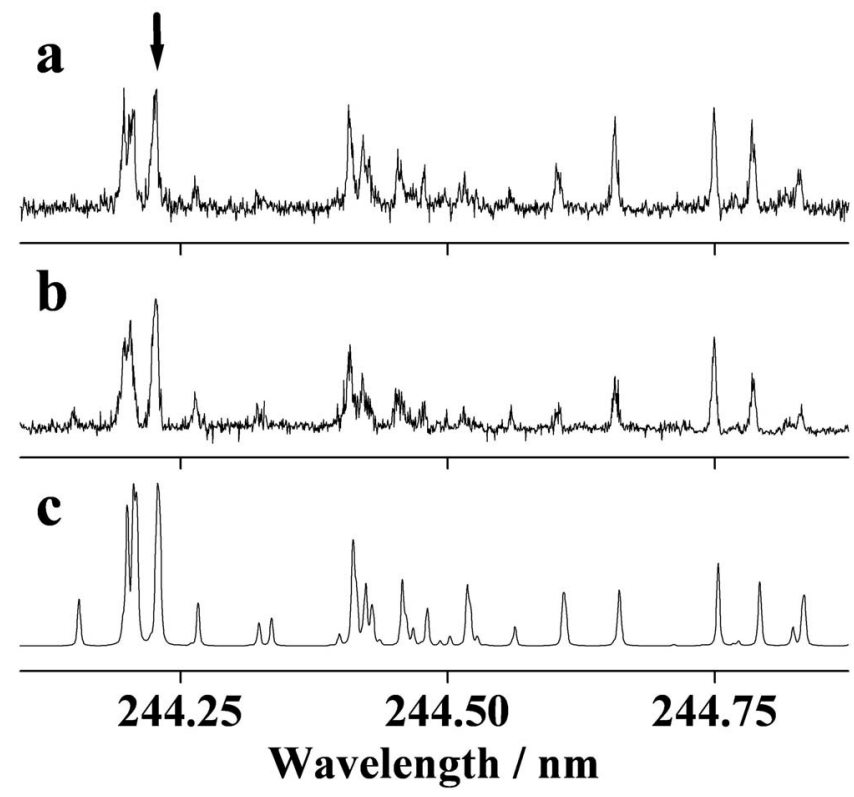

FIG. 6. REMPI excitation spectra of OH $D^{2} \Sigma^{-} \leftarrow X^{2} \Pi\left(v^{\prime}=0, v^{\prime \prime}=0\right)$ of the fast $\mathrm{OH}$ signal ( $\mathrm{TOF}=0.5 \mu \mathrm{s}$ ) from (a) fresh $\mathrm{H}_{2} \mathrm{O}_{2}$ (refer to Fig. 5). (b) After $1 \mathrm{~h}$ photoirradiation at $157 \mathrm{~nm}$ to ASW (refer to Fig. 8). (c) A simulated spectrum assuming $T_{\text {rot }}=500 \mathrm{~K}$. 


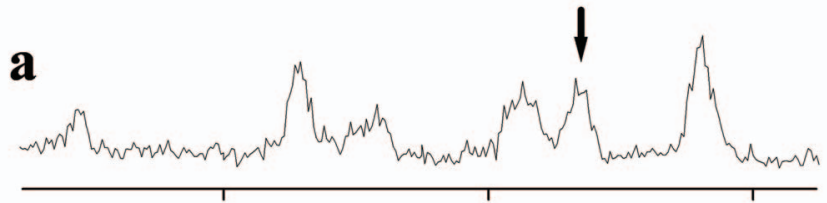

b

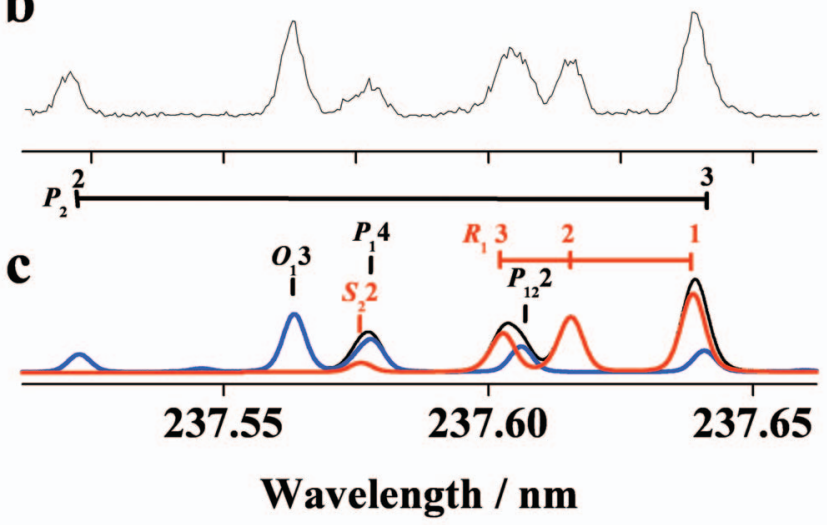

FIG. 7. REMPI excitation spectra of $D^{2} \Sigma^{-} \leftarrow X^{2} \Pi\left(v^{\prime}=1, v^{\prime \prime}=0\right)$ and $3^{2} \Sigma^{-} \leftarrow X^{2} \Pi\left(v^{\prime}=0, v^{\prime \prime}=1\right)$ of the fast $\mathrm{OH}$ signal (TOF $\left.=0.5 \mu \mathrm{s}\right)$ from (a) fresh $\mathrm{H}_{2} \mathrm{O}_{2}$ (refer to Fig. 5). (b) After $1 \mathrm{~h}$ photoirradiation at $157 \mathrm{~nm}$ to an ASW film (refer to Fig. 8). (c) A simulated spectrum assuming $T_{\text {rot }}(v=0)$ $=500 \mathrm{~K}$ and $T_{\mathrm{rot}}(v=1)=200 \mathrm{~K}$.

dosing of $\mathrm{H}_{2} \mathrm{O}$ vapor. Without intermissive deposition of water vapor on the ASW surface after each laser shot, photoproducts are accumulated on/in ASW, and hence, the secondary photolysis of the $\mathrm{H}_{2} \mathrm{O}_{2}$ photoproducts becomes appreciable in the $\mathrm{OH}$ formation. ${ }^{17}$ The $\mathrm{OH}$ signal intensity became about two times stronger than that from fresh ASW after prolonged photoirradiation because $\mathrm{OH}$ is produced from both the $\mathrm{H}_{2} \mathrm{O}_{2}$ and ASW photolysis. The contribution of the high translational temperature component $\left(T_{\text {trans }}=7500 \mathrm{~K}\right)$ due to reaction (6) becomes appreciable. The results for translational temperatures and contributions are summarized in Table I.

To verify that the $\mathrm{OH}\left(T_{\text {trans }}=7500 \mathrm{~K}\right)$ component after prolonged $157 \mathrm{~nm}$ photoirradiation of ASW came from the photodissociation of the $\mathrm{H}_{2} \mathrm{O}_{2}$ photoproduct, time evolution curves of the $\mathrm{OH}(v=0)$ and $\mathrm{OH}(v=1)$ signal intensities were measured as a function of $157 \mathrm{~nm}$ irradiation time for the fast $(t=0.5 \mu \mathrm{s})$ and slow $(t=2.5 \mu \mathrm{s})$ TOF components. Figure 9 shows the results, in which $\mathrm{OH}$ signal intensities at $t=0$ are subtracted to show the increments caused by accumulated species due to prolonged irradiation at $157 \mathrm{~nm}$. Figure 9 also includes the previously reported time evolution of $\mathrm{H}_{2} \mathrm{O}_{2}$ that was photolytically accumulated on the ASW surface by 157 nm irradiation. ${ }^{17}$ The two appearance curves correspond with each other, suggesting that the source of $\mathrm{OH}$ after prolonged $157 \mathrm{~nm}$ irradiation is photochemically produced $\mathrm{H}_{2} \mathrm{O}_{2}$.

Figure 6(b) shows the REMPI spectrum of $\mathrm{OH}(v=0)$ at $t=0.5 \mu \mathrm{s}$ and $T_{\text {rot }}=500 \pm 100 \mathrm{~K}$ by spectral simulation [Fig. $6(\mathrm{c})]$. Figure 7(b) shows a mixed band REMPI spectrum of $\mathrm{OH}(v=0$ and 1$)$ at $t=0.5 \mu$ s with $T_{\text {rot }}(v=1)=200 \pm 100 \mathrm{~K}$. The population ratio of $v=1 / v=0$ was $0.2 \pm 0.1$ by spectral simulation [Fig. 7(c)]. These results are almost the same as for $\mathrm{H}_{2} \mathrm{O}_{2}$ cocondensed on ASW described in Sec. III B,
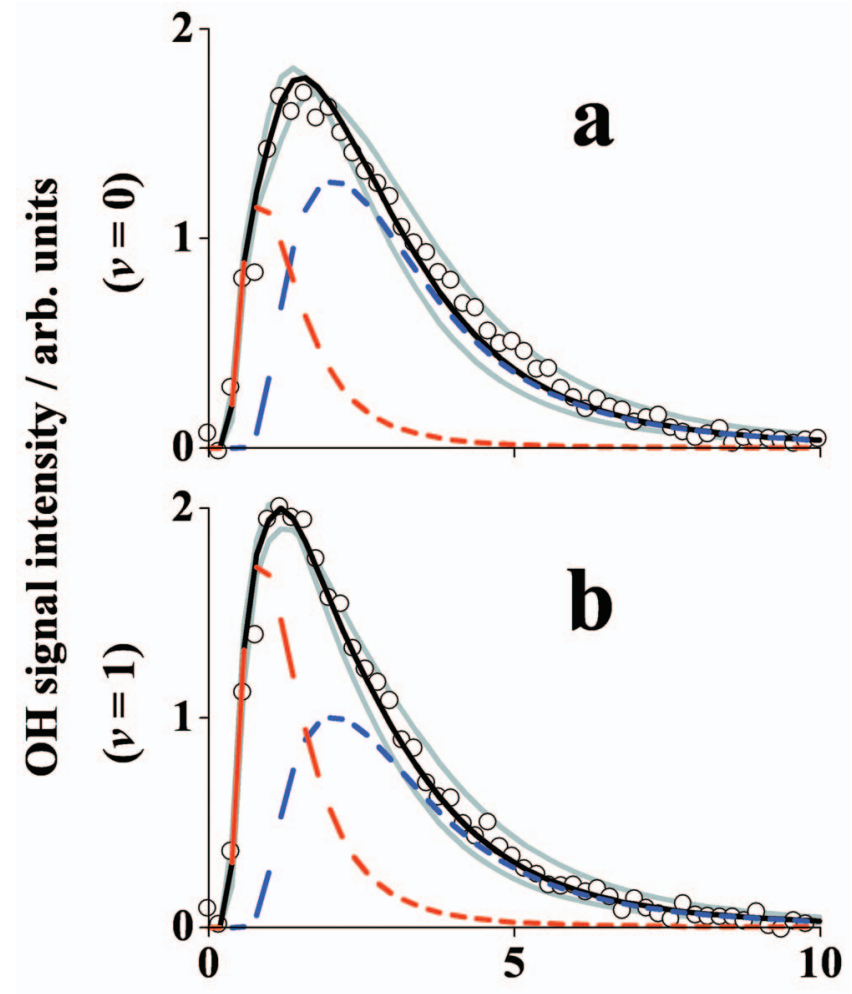

Time of flight / $\mu$ s

FIG. 8. (a) TOF spectrum of the $R(1)+R(5)$ line in $\mathrm{OH} D^{2} \Sigma^{-} \leftarrow X^{2} \Pi$ $\left(v^{\prime}=0, v^{\prime \prime}=0\right)$ from ASW after $1 \mathrm{~h}$ photoirradiation at $157 \mathrm{~nm}$. (b) The $R(2)$ line in $\mathrm{OH} 3^{2} \Sigma^{-} \leftarrow X^{2} \Pi\left(v^{\prime}=0, v^{\prime \prime}=1\right)$. The solid black curves are fits to the data derived assuming (a) $T_{\text {trans }}=7500 \mathrm{~K}(30 \%)$ and $1300 \mathrm{~K}(70 \%)$ and (b) $T_{\text {trans }}=7500 \mathrm{~K}(40 \%)$ and $1300 \mathrm{~K}(60 \%)$. Other gray curves show the error bar ranges (see Table I).

suggesting again that the source of $\mathrm{OH}$ after prolonged 157 $\mathrm{nm}$ irradiation is photochemically accumulated $\mathrm{H}_{2} \mathrm{O}_{2}$.

\section{DISCUSSION}

\section{A. Translational and internal energies of $\mathrm{OH}$ radicals from fresh amorphous solid water}

The translational energies of $\mathrm{OH}(v=0)$ and $\mathrm{OH}(v=1)$ from fresh ASW are mostly fitted with a temperature $T_{\text {trans }}=1300 \pm 300 \mathrm{~K}$. This temperature (translational energy $=5.2 \pm 1.2 \mathrm{kcal} / \mathrm{mol}$ ) is in accordance with $\sim 1600 \mathrm{~K}$ that was reported in the gas phase photodissociation of water at $157 \mathrm{~nm}$ by Mikulecky et al. ${ }^{31}$ and the MD calculations (4.5-6.0 kcal/mol) by Andersson and co-workers. ${ }^{18,19} \mathrm{~A}$ small contribution $(5 \%-10 \%)$ of the fast $\left(T_{\text {trans }}=7500 \mathrm{~K}\right)$ component would be due to the secondary photoprocess from the $\mathrm{H}_{2} \mathrm{O}_{2}$ products on ASW since the ASW surface was not completely covered with fresh $\mathrm{H}_{2} \mathrm{O}$ vapor even with intermissive $\mathrm{H}_{2} \mathrm{O}$ deposition. The rotational temperatures $T_{\text {rot }}(v=0)=400 \mathrm{~K}$ and $T_{\text {rot }}(v=1)=300 \mathrm{~K}$ are not thermally equilibrated with the ice film temperature of $90 \mathrm{~K}$. Mikulecky et $a .^{31}$ reported $T_{\text {rot }}(v=0)=620 \mathrm{~K}$ and $T_{\text {rot }}(v=1)=460 \mathrm{~K}$ for $\mathrm{OH}$ formed from the gas phase photodissociation of $\mathrm{H}_{2} \mathrm{O}$. These results suggest that we observed nascent $\mathrm{OH}$ photofragments originated from the ASW surface. 


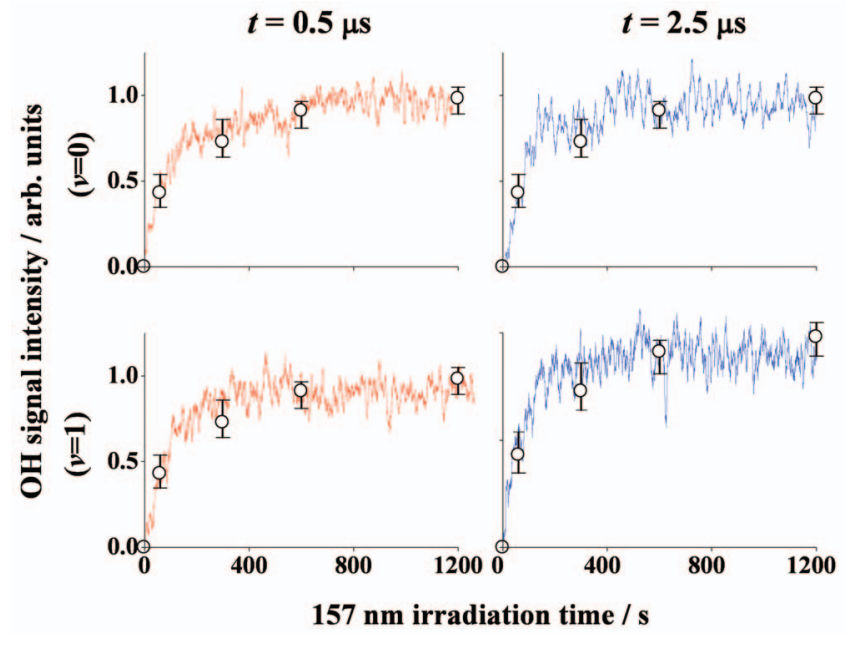

FIG. 9. Time evolution curves of the fast $(t=0.5 \mu \mathrm{s})$ and slow $(t=2.5 \mu \mathrm{s})$ components of $\mathrm{OH}[R(1)+R(5)$ for $v=0$ and $R(2)$ for $v=1]$ signals from ASW as a function of $157 \mathrm{~nm}$ irradiation time. OH signal intensities at $t=0$ are subtracted to show the increments caused by accumulated species due to $157 \mathrm{~nm}$ irradiation. Open circles represent the previously reported values for accumulation of $\mathrm{H}_{2} \mathrm{O}_{2}$ on ASW (Ref. 17).

Andersson and co-workers ${ }^{18,19}$ calculated the desorption probabilities for $\mathrm{OH}$ radicals from water ice per absorbed vuv photon in the top 6 monolayers (ML). This gave the $\mathrm{OH}$ desorption probability as function of the monolayer in which $\mathrm{H}_{2} \mathrm{O}$ was excited. Only a small fraction of $\mathrm{OH}$ radicals from the top $3 \mathrm{ML}$ can desorb with desorption probability less than $3 \%$ per ML, while most $\mathrm{OH}$ products are trapped in/on the ice at $10 \mathrm{~K}$. The lack of a surface accommodated TOF component in the present results indicates that $\mathrm{OH}$ formed in the ice bulk is readily trapped or reacts with water molecules in the ice bulk. In addition, the rotational distribution is essentially the same as those observed and calculated for gasphase $\mathrm{H}_{2} \mathrm{O}$ photolysis. We conclude that the dominant fraction of $\mathrm{OH}$ desorbed into vacuum is released from the topmost monolayer(s) of ASW.

Our present observation of vibrational distribution $v=1 / v=0 \approx 0.2$ is in fair agreement with the molecular dynamic calculations at $10 \mathrm{~K}$ by Andersson and co-workers, ${ }^{18,19}$ which predicted that desorbed $\mathrm{OH}$ has a maximum population at $v=0$ and that the amount of vibrational excitation drops only by about 30\%-50\% from one excited level to the next. The fractions of the total available energy partitioned into the different degrees of freedom in the dissociation products have also been determined. Using the translational, vibrational, and rotational distributions, it was found that $8 \%-12 \%$ of the available energy $(51.2 \mathrm{kcal} /$ mol) was partitioned into translation, 5\%-7\% into vibration, and $1 \%$ and $2 \%$ into rotation. The remainder presumably has been partitioned into the ASW matrix and translational energy of the $\mathrm{H}$ atom.

It is interesting to note the difference between the gas phase and solid phase photodynamics for $\mathrm{H}_{2} \mathrm{O}$ at $157 \mathrm{~nm}$. Hwang et al. $^{32}$ and Yang et al. ${ }^{33}$ showed that $\mathrm{OH}(v=1)$ was populated by $10 \%$ more than $\mathrm{OH}(v=0)$, and $\mathrm{OH}(v \geq 2)$ populations dropped below the detection threshold. This vibrational state distribution is different from the condensed phase results as presented in this paper. Reasons for this can be found in differences in the excited state potentials, dissipation of energy, and/or the dynamics of the photodissociation process. The two first cases were already discussed in some depth by Andersson and co-workers. ${ }^{18,19}$ In short, there is evidence that the surrounding water molecules affect the electronically excited state of $\mathrm{H}_{2} \mathrm{O}$ by lowering the intramolecular part of the excitation energy. This was also found in the high-level electronic structure calculations by Chipman, ${ }^{34,35}$ which showed that the first excited state potential energy surface of $\mathrm{H}_{2} \mathrm{O}$ is significantly affected by neighboring $\mathrm{H}_{2} \mathrm{O}$ molecules. This would lead to somewhat different product energy distributions.

The translational energy distribution of the desorbing $\mathrm{H}$ atoms seemed to be affected by this effect, possibly combined with the dissipation of excess energy. ${ }^{14}$ This dissipation of energy will most likely proceed through energy transfer to vibrational modes of water molecules in the ice and/or through reaction of energetic $\mathrm{H}$ atoms with $\mathrm{H}_{2} \mathrm{O},{ }^{14-16}$

$$
\mathrm{H}+\mathrm{H}_{2} \mathrm{O} \rightarrow \mathrm{H}_{2}+\mathrm{OH} \text {. }
$$

The good agreement between the classical MD calculations and experiments could be fortuitous or there could be a more fundamental reason for this. Generally, full quantum dynamics calculations are required to obtain reliable product quantum state distributions. This has been done for the case of gas-phase photodissociation of $\mathrm{H}_{2} \mathrm{O}$ by van Harrevelt and van Hemert. ${ }^{36}$ However, in the case of multidimensional systems such as a liquid or a solid the most important quantum effects are often "static," i.e., inclusion of zero-point energy, rather than dynamic interference effects. ${ }^{37,38}$ The reason for this is the rapid loss of coherence that is common in condensed phases.

\section{B. OH radical formation by the secondary photoprocess of $\mathrm{H}_{2} \mathrm{O}_{2}$}

In their MD calculations, Andersson and co-workers ${ }^{18,19}$ studied the mobility of $\mathrm{OH}$ radicals following the photolysis of water ice. The $\mathrm{OH}$ radicals formed in the ice move only at a maximum distance of $5 \AA$ at $10 \mathrm{~K}$. However, $\mathrm{OH}$ radicals formed from photodissociation in the top $3 \mathrm{ML}$ are able to move up to more than $60 \AA$. This indicates that the $\mathrm{OH}$ radicals that have diffused along the surface and have dissipated some of their internal energy to the surface in the process are likely trapped at the surface site but not desorbed. On the other hand, Petrik et al. ${ }^{13}$ reported the low-energy electron-stimulated production of molecular oxygen from thin ASW films and proposed that the electron-stimulated migration of $\mathrm{OH}$ or $\mathrm{OH}^{-}$to the vacuum interface, where they react and produce molecular oxygen, occurs via transport through the hydrogen bond network of the ASW. In either case, it is speculated that the recombination of $\mathrm{OH}$ to form $\mathrm{H}_{2} \mathrm{O}_{2}$ occurs more readily at the surface of ASW compared to the bulk. In fact, Yabushita et al. ${ }^{17}$ reported in their vuv photolysis experiments that $\mathrm{H}_{2} \mathrm{O}_{2}$ was subsequently produced on the water ice surface at $90 \mathrm{~K}$ presumably due to recombination of photolytically produced $\mathrm{OH}$.

Figure 9 shows the appearance behavior of $\mathrm{OH}$ signals mainly due to reaction (6), the secondary photodissociation 
of surface-bound $\mathrm{H}_{2} \mathrm{O}_{2}$ formed via reaction (3). The highertranslational temperature $\left(T_{\text {trans }}=7500 \mathrm{~K}\right)$ of Figs. 5(a) and 5 (b) is attributed to the larger $E_{\text {avail }}$ in reaction (6) than reaction (5). In addition, the translational and internal energies for the $\mathrm{OH}$ radicals from $\mathrm{H}_{2} \mathrm{O}_{2}$ directly condensed on ASW are in good accordance with those for the $\mathrm{OH}$ radicals following the prolonged $157 \mathrm{~nm}$ irradiation of ASW. Therefore, the contribution of $\mathrm{OH}$ radicals from other by-products such as $\mathrm{HO}_{2}$ formed as follows would be small, since (a) $\mathrm{HO}_{2}$ is produced from a three-step reaction of $\mathrm{OH}+\mathrm{H}_{2} \mathrm{O}_{2}$, where $\mathrm{H}_{2} \mathrm{O}_{2}$ is produced from $\mathrm{OH}+\mathrm{OH}$, and (b) $\mathrm{HO}_{2}$ disappears at elevated temperatures, ${ }^{7}$

$$
\begin{aligned}
& \mathrm{H}_{2} \mathrm{O}_{2}+h \nu \rightarrow \mathrm{H}+\mathrm{HO}_{2}, \\
& \mathrm{H}_{2} \mathrm{O}_{2}+\mathrm{OH} \rightarrow \mathrm{H}_{2} \mathrm{O}+\mathrm{HO}_{2}, \\
& \mathrm{HO}_{2}+h \nu \rightarrow \mathrm{O}+\mathrm{OH} .
\end{aligned}
$$

\section{CONCLUSION}

In the $157 \mathrm{~nm}$ irradiation experiments on ASW at $90 \mathrm{~K}$, we have measured the translational and rotational temperatures and vibrational distributions for $\mathrm{OH}(v=0$ and 1) that are the products from surface $\mathrm{H}_{2} \mathrm{O}$ of ASW as well as the products from $\mathrm{H}_{2} \mathrm{O}_{2}$ that is photochemically produced on the surface of ASW. OH from $\mathrm{H}_{2} \mathrm{O}$ is characterized by a translational temperature of $1300 \mathrm{~K}$, while that of $\mathrm{OH}$ from $\mathrm{H}_{2} \mathrm{O}_{2}$ is $7500 \mathrm{~K}$. We found that the contribution of the secondary photolysis of accumulated photoproducts is appreciable in the condensed phase photoprocesses of water ice.

\section{ACKNOWLEDGMENTS}

This work is supported by a grant in aid from JSPS (Grant No. 20245005).

${ }^{1}$ V. Poterya, M. Fárník, M. Ončák, and P. Slavíček, Phys. Chem. Chem. Phys. 10, 4835 (2008).

${ }^{2}$ J. D. Thrower, M. P. Collings, M. R. S. McCoustra, D. J. Burke, W. A. Brown, A. Dawes, P. D. Holtom, P. Kendall, N. J. Mason, F. Jamme, H. J. Fraser, I. P. Clark, and A. W. Parker, J. Vac. Sci. Technol. A 26, 919 (2008).

${ }^{3}$ C. L. Thomsen, D. Madsen, S. R. Keiding, J. Thøgersen, and O. Christiansen, J. Chem. Phys. 110, 3453 (1999).

${ }^{4}$ M. Seki, K. Kobayashi, and J. Nakahara, J. Phys. Soc. Jpn. 50, 2643 (1981)

${ }^{5}$ L. J. Stief, W. A. Payne, and R. B. Klemm, J. Chem. Phys. 62, 4000 (1975).

${ }^{6}$ A. A. Y. M. Ung, Chem. Phys. Lett. 28, 603 (1974).

${ }^{7}$ P. A. Gerakines, W. A. Schutte, and P. Ehrenfreund, Astron. Astrophys. 312, 289 (1996).
${ }^{8}$ J. A. Ghormley and C. J. Hochanadel, J. Phys. Chem. 75, 40 (1971).

${ }^{9}$ M. S. Westley, R. A. Baragiola, R. E. Johnson, and G. A. Baratta, Nature (London) 373, 405 (1995).

${ }^{10}$ M. S. Westley, R. A. Baragiola, R. E. Johnson, and G. A. Baratta, Planet. Space Sci. 43, 1311 (1995).

${ }^{11}$ G. A. Kimmel and T. M. Orlando, Phys. Rev. Lett. 75, 2606 (1995).

${ }^{12}$ G. A. Kimmel, R. G. Tonkyn, and T. M. Orlando, Nucl. Instrum. Methods Phys. Res. B 101, 179 (1995).

${ }^{13}$ N. G. Petrik, A. G. Kavetsky, and G. A. Kimmel, J. Chem. Phys. 125, 124702 (2006).

${ }^{14}$ A. Yabushita, D. Kanda, N. Kawanaka, M. Kawasaki, and M. N. R. Ashfold, J. Chem. Phys. 125, 133406 (2006).

${ }^{15}$ A. Yabushita, T. Hama, D. Iida, N. Kawanaka, M. Kawasaki, N. Watanabe, M. N. R. Ashfold, and H. P. Loock, Astrophys. J. 682, L69 (2008).

${ }^{16}$ A. Yabushita, T. Hama, D. Iida, N. Kawanaka, M. Kawasaki, N. Watanabe, M. N. R. Ashfold, and H. P. Loock, J. Chem. Phys. 129, 044501 (2008).

${ }^{17}$ A. Yabushita, T. Hama, D. Iida, and M. Kawasaki, J. Chem. Phys. 129, 014709 (2008).

${ }^{18}$ S. Andersson, A. Al-Halabi, G. J. Kroes, and E. F. van Dishoeck, J. Chem. Phys. 124, 064715 (2006).

${ }^{19}$ S. Andersson and E. F. van Dishoeck, Astron. Astrophys. 491, 907 (2008).

${ }^{20}$ K. I. Öberg, H. Linnartz, R. Visser, and E. F. van Dishoeck, Astrophys. J. 693, 1209 (2009).

${ }^{21}$ M. Kh. Karapet'yants and M. K. Karapet'yants, Handbook of Thermodynamic Constants of Inorganic and Organic Compounds (Humphrey Science Publishers, Ann Arbor, 1970).

${ }^{22}$ A. J. Matich, M. G. Bakker, D. Lennon, T. I. Quickenden, and C. G. Freeman, J. Phys. Chem. 97, 10539 (1993).

${ }^{23}$ A. Yabushita, Y. Inoue, T. Senga, M. Kawasaki, and S. Sato, J. Phys. Chem. B 106, 3151 (2002).

${ }^{24}$ M. Kawasaki, Appl. Surf. Sci. 135, 115 (1998).

${ }^{25}$ M. E. Greenslade, M. I. Lester, D. C. Radenovic, A. J. A. van Roij, and D. H. Parker, J. Chem. Phys. 123, 074309 (2005).

${ }^{26}$ A. Yabushita, Y. Inoue, T. Senga, M. Kawasaki, and S. Sato, J. Phys. Chem. A 108, 438 (2004).

${ }^{27}$ F. M. Zimmermann and W. Ho, J. Chem. Phys. 100, 7700 (1994).

${ }^{28}$ F. M. Zimmermann and W. Ho, Surf. Sci. Rep. 22, 127 (1995).

${ }^{29} \mathrm{C}$. M. Western, PGOPHER, a program for simulating rotational structure, University of Bristol, http://pgopher.chm.bris.ac.uk.

${ }^{30}$ K. P. Huber and G. Herzberg, Molecular Spectra and Molecular Structure IV. Constants of Diatomic Molecules (Van Nostrand Reinhold, New York, 1979).

${ }^{31}$ K. Mikulecky, K. H. Gericke, and F. J. Comes, Chem. Phys. Lett. 182, 290 (1991).

${ }^{32}$ D. W. Hwang, X. F. Yang, and X. M. Yang, J. Chem. Phys. 110, 4119 (1999).

${ }^{33}$ X. F. Yang, D. W. Hwang, J. J. Lin, and X. Ying, J. Chem. Phys. 113, 10597 (2000).

${ }^{34}$ D. M. Chipman, J. Chem. Phys. 122, 044111 (2005).

${ }^{35}$ D. M. Chipman, J. Chem. Phys. 124, 044305 (2006).

${ }^{36}$ R. van Harrevelt and M. C. van Hemert, J. Chem. Phys. 114, 9453 (2001).

${ }^{37}$ J. A. Poulsen, G. Nyman, and P. J. Rossky, Proc. Natl. Acad. Sci. U.S.A. 102, 6709 (2005).

${ }^{38}$ J. A. Poulsen, G. Nyman, and P. J. Rossky, J. Chem. Theory Comput. 2, 1482 (2006). 